\title{
Building innovative, inclusive and resilient global value chains
}

\author{
Venkatachalam Anbumozhi $^{1} \cdot$ Kaliappa Kalirajan $^{1}$
}

Published online: 27 October 2021

(c) The Author(s), under exclusive licence to Institute for Social and Economic Change 2021

\begin{abstract}
Future is an unpredictable certainty that everyone would like to control. With all the advancements of technology, the Future remains out of grasp. However, the closest thing that one can do to be there is to prepare oneself in such a way that no matter what the Future will be, one is able to face it. With anything that is unknown, the preparation needs to be as broad-based as possible to be able to handle different possibilities. The current situation across the world is such a situation with unpredictable certainty with the spread of the different variants of the COVID-19 virus. Evidence-based research has revealed that the strategic ability of some Global Value Chains (GVC) has facilitated recovery from inevitable vulnerabilities and unexpected events, such as the COVID-19 pandemic more effectively than others. This has more recently triggered a policy debate about Innovative, Inclusive and Resilient Value Chains. Innovative, Inclusive and Resilient Value Chains are in a way broad-based preparation that aim at developing the adaptive capability of them to prepare for the unexpected events and to respond to disruptions and recover from them. Within this context, this special issue will analyse the process of building Innovative, Inclusive and Resilient Value Chains, and their impact on the socio-economic development of Asia and beyond.
\end{abstract}

\section{Introduction}

The increasing complexity of the present economic system and the strong interdependencies existing between production activities taking place in different places make modern societies vulnerable to crisis. The global value chain is a paradigmatic example of a socioeconomic structure on which the impacts of unexpected events propagate rapidly through the system. The climate induced natural disaster and manmade financial crisis, which affect the integrated production process, have become important factors influencing the efficiency of the present Global Value Chains (GVC). During the last decade, a large set of studies have investigated the direct impacts generated on specific geographical areas by the GVC. However, a smaller number of analyses have quantified the cascading economic effects of extreme weather events and economic crisis on the production networks. The

Kaliappa Kalirajan

kaliappa.kalirajan@anu.edu.au

1 Economic Research Institute for ASEAN and East Asia, Jakarta, Indonesia 
great complexity of the global economic system, coupled with methodological and data gaps make it difficult to estimate the domino effects of unexpected events.

On the other hand, for the past ten years, GVC vulnerability and its managerial counterpart supply chain risk management have received considerable attention from academics and policy makers. The impact of the one entity in the GVC, e.g. physically or financially, can lead to a number of entities closing down and in some instances the whole supply chain shuts down. The risk implications of the entwined regional and global marketplace that characterise today's Asian regional value chains have been evidenced vividly in the case of the 2011 Japanese earthquake, Thailand floods, and the latest COVID-19 pandemic. Moreover, incidents like the seemingly unlikely volcano eruption in Indonesia make companies and policymakers aware of how little control they have over many of the vulnerabilities that they are confronted with. Still, some societies appear to be able to weather the occurrence of hazardous events more effectively than other is. They can sustain by coming back to normality or to a new state from which they can operate.

The apparent ability of some GVCs to recover from inevitable vulnerabilities more effectively than others has more recently triggered a policy debate about Innovative, Inclusive and Resilient Value Chains. Whereas GVC risk management focuses on the identification and management of risks for the networked firms in order to reduce their? Vulnerability, Innovative, Inclusive and Resilient Value Chains aim at developing the adaptive capability of them to prepare for the unexpected events and to respond to disruptions and recover from them. This is also based on the underlying assumption that not all vulnerabilities and risk events are preventable and residual management strategies and business continuity plans vary.

Within this context, this special issue will analyse the process of building Innovative, Inclusive and Resilient Value Chains, and their impact on the socio-economic development of Asia and beyond.

\section{The setting}

Since the 1980s as globalisation deepened, an increasing number of firms, particularly small and medium-sized enterprises (SMEs) in the Association of Southeast Asian Nations (ASEAN), participated in global supply chains typically at the intermediate and final assembly stages. ASEAN and East Asia's export-oriented open trade policies have contributed to the birth of these value chains and the accompanying high economic growth.

Nevertheless, these complex supply chains are inherently vulnerable to external shocks and disruptions. Cyclones, earthquakes, economic crises, and epidemics are business risks companies have been facing for decades. Asia's unique vulnerability to climate change, disasters, and diseases means that building resilience is a business continuity issue for every company along the supply chain (Fig. 1). All Asian countries fared poorly in the 2020 World Risk Index on strengthening their abilities to prepare and adapt to extreme events.

However, a recent study by the Economic Research Institute for ASEAN and East Asia (ERIA)-Springer on supply chain resilience that explored the vulnerability of businesses to unpredictable risks found that companies are now much more concerned about external uncertainties than in previous decades (Anbumozhi et al. 2020).

In recent times, the COVID-19 pandemic has hit global supply chains at an unprecedented scale and speed. In Asia, the lockdowns have caused the closure of businesses, 


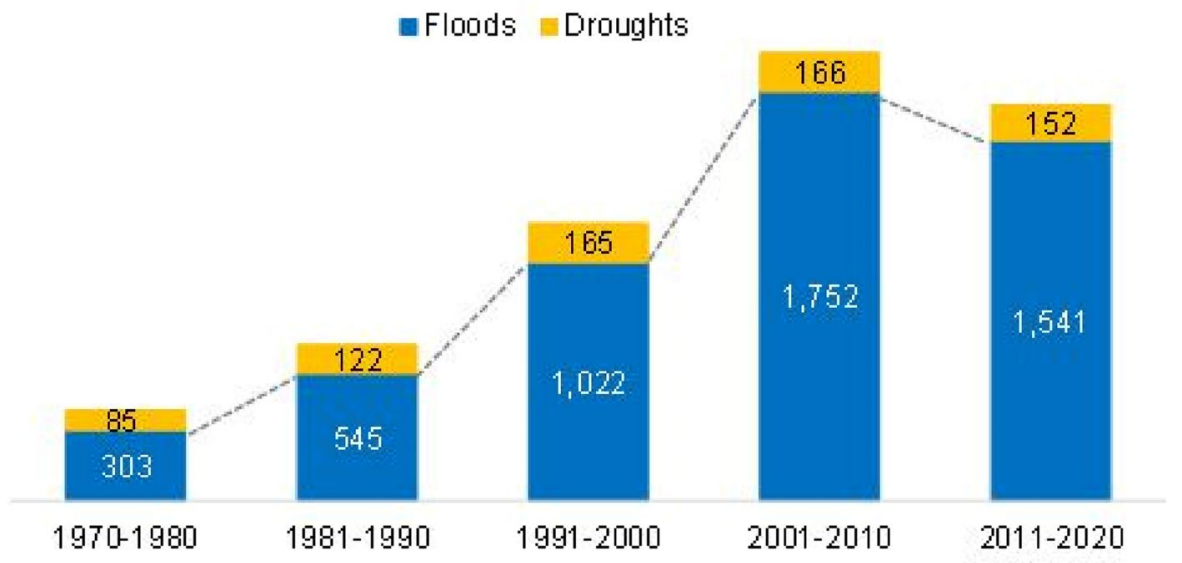

Fig. 1 Number of Flood and Drought Events in Asia. Source: Data from EM-DAT, CRED/UNLouvain, Brussels, Belgium (www.emdat.be). Cited in Kumse et al. (2021)

the stoppage of factory outputs, and disruption to manufacturing industries and their supply networks. The COVID-19 pandemic is putting Asia's supply chains to the test; firms need to assess their corporate risks and build resilience. Combined with the financial impact of a global economic downturn, supply chain resilience is crucial for the survival of individual companies in different sectors within and across countries. Drawing on the evidence-based research, the objective of this special issue is to disseminate the experiences of global value chains located in some of the Asian countries and in Austria in the European region with respect to innovating the inclusion, competitiveness, and resilience in their operations.

\section{Short-term measures}

A good resilience strategy can achieve both the short-term goal of safeguarding business operations while working with governments towards the long-term goal of building resilient economies. Several natural disaster events in the last two decades have caused shortterm supply shocks, however they have not reduced operational capacity of firms, and exports bounced back more quickly than expected.

Those crises have not reversed the patterns of globalisation but accelerated two longterm trends in the global supply chain. First, leading firms used the crisis to consolidate their supply base further by institutionalising Business Continuity Plans (BCP), a corporate strategy that promotes a strategic buyer-seller relationship, to ensure continuity of operations with minimal service outage and to act as a source of resilience.

Second, when demand rebounds after a crisis, the growth of intra-regional trade creates opportunities for new firms to upgrade to global value chains. While firms are responsible for addressing supply and demand shocks with appropriate corporate insurance mechanisms, a multi-stakeholder approach of adopting BCPs that involves government support for early warning systems, information sharing, capacity building, and technical support are important approaches to enhance supply chain resilience. 


\section{Recovery, resilience, and competitiveness}

Medium-term actions for enhanced resilience include better understanding and managing the supplier networks, increasing production efficiency, and systematically developing strategic changes to harness potential new markets.

A prolonged pandemic or deeper structural impact could delay the recovery of firms by returning them to their pre-COVID supply capacity. In the 1997 Asian financial crisis, a liquidity problem, and a collapse of demand in some major economies rippled down along selected value chains, but many companies recovered quickly with banking sector support, resulting in full recovery within a year or two. On the other hand, the COVID-19 pandemic is of higher magnitude and has dramatically increased a range of pathways that firms, particularly small businesses, could take to encompass multiple risks along the global supply chain.

The COVID-19 induced fall in global demand, particularly, led to a drop in demand for intermediate goods destined for assembly in China, Korea, and Japan. Due to heavy reliance on imported inputs from Singapore, Malaysia, Indonesia, Thailand, and Vietnam, they effectively transferred a large portion of their negative export demand shocks to their ASEAN partners. Although export-centred economic growth has largely been a story of rising Asian companies' supplier capabilities, there has been growing recognition of the key role that final export markets play in the process. For example, it is imperative for companies that sell their products to advanced economies like Japan, the European Union (EU), and the United States (US) to be aware of new opportunities for green growth, which have been invigorated by the pandemic recovery stimulus packages.

\section{New resilient supply chain models}

Enhancing the resilience of firms in the longer-term involves building new digital infrastructure and joining international agreements on industry-wide standards. More than three decades of focus on optimisation to minimise production costs, reduce inventories, and drive up capital utilisation has resulted in lean global supply chains, thus removing buffers and flexibility of Asian companies, particularly small businesses, who are no longer able to absorb disruptions. The pandemic many lead companies to rethink and transform these lean production networks.

Fortunately, new technologies are emerging, which could dramatically improve resilience and competitiveness. The traditional linear supply chain model is transforming into digital production networks, where functional silos could be broken down, and organisations can become connected to their supplier networks to enable end-to-end traceability, collaboration, agility, and cost optimisation.

Leveraging advanced digital technologies such as the internet of things (IoT), artificial intelligence (AI), robotics, blockchain, cognitive computing, augmented and virtual reality help to anticipate and meet future competitive and resilience challenges. Keeping the competitiveness in global supply chains requires investment in people, skills and high-quality digital infrastructure and encouragement of strong industry-university linkages. The Sendai Framework, a non-binding international agreement by the United Nations (UN), and the ASEAN Agreement on Disaster Management and Emergency Response (AADMER) recognise the private sector as a key stakeholder, responsible for building businesses that 
make risk-informed decisions and develop resilient supply chains. Committing to such international agreements will be a significant modifier for companies to collectively act on industry-wide resilience standards. Consciously building resilience will be the better recipe for long-term.

In the future perhaps, catastrophic events, such as the variants of COVID-19 will emerge more frequently but with less prediction. They will unfold faster varied impacts on human health, which have bearings on productivity and growth of firms and eventually on the overall development of the nation. Firms cannot afford to be either inflexible or imprudent. Theory of the firms argues that those unwilling to take sufficient risk will not respond or innovate to meet changing circumstances. At the same time, those who are focused on financials, growth, or expansion may take on the risk that kills their long-term success. Hence, firms should be focusing not only on short-term earnings, but also sustaining earnings growth in the long-term. However, in reality across industries, most companies have remained persistently focused on near- and medium-term earnings, typically assuming ongoing smooth business conditions. Thus, there is a greater need for strengthening innovation, inclusion and resilience strategies at the firm and industry levels to consistently protect growth against the catastrophic events both in the short- and long-terms. Figure 2 provides the schematic representation of the available opportunities for a typical food value chain to achieve innovation, inclusion, and resilience systematically.

The successful business design and operation strategies of GVC are determined by how efficiently the physical factors of production are combined with the human capital. Technology determines how effectively and efficiently the factors of production can be combined to produce the maximum possible outputs at the least costs. Technological progress to sustain firms' profits is promoted by research and development (R\&D). Policymaking for science, technology, and innovation (R\&D) is stepping into a new era in the twenty-first century within a highly integrated production network, making it more challenging to capture the impact of R\&D investment from an evidence-based approach.

Drawing on the evidence-based research, this special issue has presented a set of 8 empirical studies addressing some of the important above discussed concerns regarding the operations of GVC across the countries in the region and in Europe.

To unfold the paradox of the R\&D spillover effect spared in the global supply chain, the paper by Michael Huang has used a computable general equilibrium (CGE) model with the GTAP database v10 to analyse the impact of Japan's public R\&D investment to the world. The focus of the paper is on key sectors of the global supply chain, namely, chemical and pharmaceutical, electronic equipment, machinery, and transportation equipment

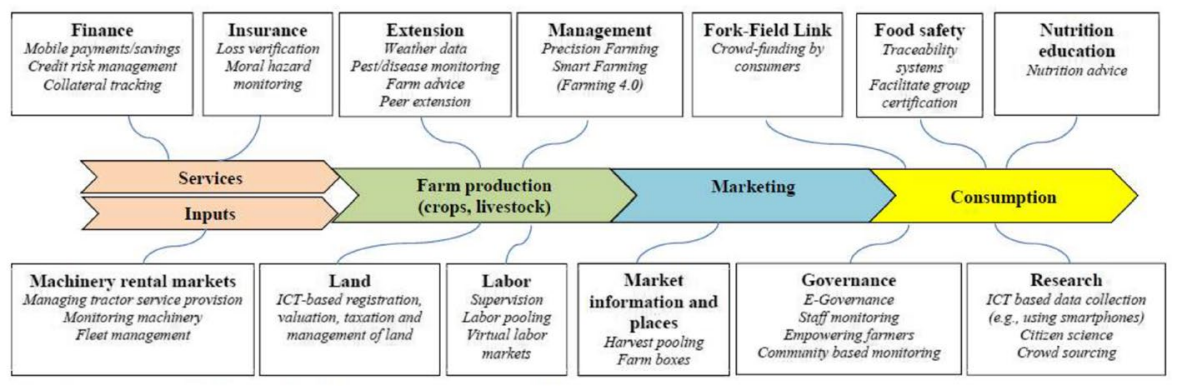

Fig. 2 Opportunities for Innovation, inclusion, and resilience in a typical Food Vale Chain 
to examine their outputs, external trades, and welfare. The simulation results show a significant increase in Japan's output and export for chemical and pharmaceutical, electronic equipment, and transportation equipment. In contrast, the economic indicators of China reveal a negative impact, implying a structural change in the composition of the production network. It is notable to see a higher economic integration of Oceania within the region through its vibrant production and trades. The study provides a comprehensive global analysis on production networks and insights for evaluating the R\&D investment spillover effects.

In terms of improving and sustaining earnings from agricultural and allied sectors during unforeseen circumstances, such as the COVID-19 pandemic, the next paper by Suresh Chandra Babu argues how innovative policy measures can be used to build a resilient system to overcome the negative impact of the unexpected. In India, the commercial based already fragile horticulture industry is now facing a double burden of a weak value chain management system as well as perishability of produce (fresh fruits and vegetables), in this pandemic season. Also, the strict enforcement of lockdown has altered both demand and supply factors, which in turn have shocked various linkages in the value chain of fresh fruits and vegetables. This paper dissects the value chain management of grapes and processed products, such as juice, wine, and raisins in Maharashtra, the largest producer of grapes in India. A Value Chain Analysis (VCA) has been carried out by computing the degree of value addition to uncover the rupture points caused by the pandemic as well as advocate policy measures to build a resilient system. Using the insights from the VCA results plus the demand and supply shocks, various policy measures are elucidated to strengthen the grape value chain.

As a major food producing area in Indonesia, Java is threatened by medium to a high level of natural disaster vulnerability that will certainly affect the national food system. The paper by Nunung Nuryartono aims to analyse the determining factors of the food security index as a proxy of regional resilience, especially in Java. The sample used in this analysis is derived from districts throughout Java in the years 2017-2018. The panel data regression models are used for empirical analysis. The results showed that disaster vulnerability is very influential on food security at the district level. The other affecting factors for food security at the regional level are socio-economic dimensions such as inflation, poverty, and gross domestic regional product (GDRP) per capita. Policies are necessary to prevent food inflation by stabilising prices, ensuring effective, and efficient supply lines (under various conditions, including at the occurrence of natural disasters), as well as government market operations. Further implications for the food system and the food resilience are the necessity to build an integrated food system from production, distribution channels to guarantee the availability of sufficient food supply in every district. Increased connections between the producer and the consumer regions potentially increase resilience in both the production and consumption areas.

In terms of improving and sustaining earnings from manufacturing and allied sectors, such as international trade, the next paper by Shandre Mugan Thangavelu examines the effects of economic shocks on the productive performance of manufacturing firms in Vietnam using the firm-level data from 2004-2008. The paper also scrutinises the effects of economic shocks on the productive performance of firms in terms of access to linkages, spillovers, and ownership structures in terms of foreign and domestic firms. The economic shocks such as the global financial crisis tend to have a greater impact on domestic firms and state-owned enterprises (SOEs). The findings suggest that the local private enterprises did not receive positive foreign horizontal and backward spillovers from the multinational enterprises (MNEs). The results also indicate that trade policies (effective rate of 
protection) that protect domestic firms tend to experience a negative impact on their productive performance during the economic crisis.

The following paper by Willem Thorbecke examines the impact of commodity prices and manufactured goods prices on Indonesian exports. Indonesian rupiah depreciated 50 percent between July 2011 and February 2020. Empirical results of this paper indicate that while Indonesian banks are exposed to depreciation, exports are not stimulated by depreciations. The findings also indicate that Indonesia's export price index is positively correlated with commodity prices and negatively correlated with manufactured goods prices. Exporting more manufactures would reduce Indonesia's exposure to volatile commodity prices and allow depreciation to stimulate exports. This paper considers several steps that Indonesia could take to increase its manufacturing exports.

A perception about the emergence of global value chains is whether those are exclusive to urban and urban satellite cities due to their infrastructure and logistics. The inclusiveness of the global value chains can be easily seen through the existing global rural value chains relating to business activities in non-central locations all over the world. Meinhard Briling in the next paper argues that rural supply chains contain almost all global agricultural production, a major part of global tourism and minor shares of industry and other services than tourism. Their generated value is more dependent on climate and extreme weather events than what is the case with urban value chains. In this paper, concepts of disaster vulnerability and disaster resilience to rural value chains are discussed through case studies of global rural value chains in ASEAN, Japan, Asia, and Austria. The empirical analyses indicate that the value at risk in a given location widely depends on the susceptibility of people and the environment to a natural disaster, the costs to repair and possibilities to innovate. Along with economic growth, disasters accelerate transformations in rural value chains and strive to become more global while contracting in their local extensions.

The paper by Karunathilake Kankanige is aimed at analysing the positive and negative impacts of COVID-19 from a sociological perspective. Also, it has a proposal for the control of the disease as well as the entire socio-economic, environmental, and political atmosphere in a country, while particularly giving more consideration to South Asia. The proposed actions are analysed in a short-term, mid-term, and long-term basis and any expert and social worker who is involved in the pandemic control process can gain an insight into what to do and how to perform their tasks. A sociological analysis on COVID-19 is very important because there is a wing comprising dominant medical experts in the control and management of the disease. The article emphasises the importance of a sociological analysis in a pandemic situation. Naturally, anyone would think of a pandemic situation in very negative terms due to its emotional, socio-economic, environmental, political, and cultural factors. However, it is also positive due to certain factors that help to reintegrate and reorganise the social system as a whole.

The productivity of the human capital is dependent on the access to and availability of health facilities. The final paper by Minquan Liu highlights the supply-chain approach to develop the concept of a hazard resilient healthcare system (HRHS) and explores ways how this might be achieved. It argues that a supply chain approach may provide a better, more robust, and in many ways more realistic, approach to enhance the hazard-resilience of national healthcare systems. Within such an approach, capabilities of the local actors (local health authorities and healthcare providers) in a pandemic or disaster-prone situation remain important and should be further strengthened, but international support and assistance in times of emergency should also be a key plank of the system. In a changing world with more frequent high-impact pandemics and disasters, such international support need not be one way, but both ways. A system of mutual support may be developed by 
forming an effective international common pool of capability in responding to the health needs when a major disaster occurs anywhere in a region or globe. Even though serious limitations exist in the current thinking on HRHS, significant progress has been made on the international humanitarian assistance front, especially in the ASEAN region. While developments on this front have not been a part of the purview of the current international thinking on HRHS, it is argued that they may well form an important cornerstone in a typical future national HRHS.

Acknowledgements Comments and suggestions by Professor Meenakshi Rajeev on an earlier version have been acknowledged with many thanks.

Funding This study did not receive financial assistance from any funding sources.

\section{Declarations}

Conflict of interest There is no conflict of interest.

\section{References}

Anbumozhi V, Kimura F, Thangavelu SM (eds) (2020) Supply chain resilience: reducing vulnerability to economic shocks, financial crises, and natural disasters. ERIA-Springer, Singapore

Kumse K, Sonobe T, Rahut D (2021) Climate change impacts in Asia are all essentially a water story. Asia Pathways, Asian Development Bank Institute, Tokyo, 14 May

Publisher's Note Springer Nature remains neutral with regard to jurisdictional claims in published maps and institutional affiliations. 